\title{
Distinguishing Three Classes of Androgenetic Alopecia based on Concerns in Youth: Latent Class Analysis of a Cross-Sectional Survey
}

\section{BUSSABONG CHANCHEEWA}

Chulalongkorn University Faculty of Medicine

\section{STEPHEN KERR}

Chulalongkorn University Faculty of Medicine

CHAICHANA NIMNUAN

Chulalongkorn University Faculty of Medicine

PRAVIT ASAWANONDA

Chulalongkorn University Faculty of Medicine

KOBPAT PHADUNGSAKSAWASDI ( $\square$ kobpat.p@chula.ac.th )

Faculty of Medicine, Chulalongkorn University https://orcid.org/0000-0001-7890-5078

\section{Research}

Keywords: Androgenetic alopecia, Latent class analysis, Quality of life, Perception

Posted Date: November 17th, 2020

DOI: https://doi.org/10.21203/rs.3.rs-105945/v1

License: @ (1) This work is licensed under a Creative Commons Attribution 4.0 International License. Read Full License 


\section{Abstract}

Background: While androgenetic alopecia (AGA) is a common condition, the concerns of youth about this condition, and how these concerns influence quality of life, personal well-being and health behaviour have been not been thoroughly investigated.

Methods: Thai youth were asked to complete an AGA-related questionnaire including the dermatology life quality index, to assess their concerns and the clinical relevance. Latent class analysis was used for data analysis.

Results: Data from 278 youth were collected. The mean participant age was 22 years ( $S D=0.79$ ), and $57 \%$ of the participants were men; $94.6 \%$ of the participants reported any hair loss, mostly in the AGA severity of grade 1-2. A three-class model showed the best fit. Latent class 1 (LC1) participants (58\%) had the lowest probabilities of concerns regarding AGA. LC2 participants (22\%) had a generally low probabilities of AGA concerns, except when they were flirting, when they were with their lover and regarding how their hair looked when they were photographed. LC3 participants (20\%) were the most concerned about AGA in all aspects. Compared with LC1 participants, LC3 participants were more often to use more than 3 hair styling products (relative risk, $6.7 ; 1.5-29.6 ; P=0.013$ ) and their AGA severity was more severe in both males (relative risk, 3.2;1.1-8.9; $\mathrm{P}=0.023$ ) and females (relative risk,10.2; 3.3-31.0; $\mathrm{P}=<0.001$ ).

Conclusions: Youths who are more worried about AGA experience higher AGA severity and poorer quality of life, and are more likely to use multiple hair styling products.

\section{Background}

Androgenetic alopecia (AGA), also known as male or female pattern hair loss, is one of the most common dermatological problems. It is also the most common type of hair loss(1). AGA is characterized by miniaturization of hair follicles mainly in the frontal and parietal areas of the scalp due to dihydrotestosterone and genetic factors $(2,3)$. The age of onset in Asians is usually around the 3rd and 4th decades. Oral 5-alpha-reductase inhibitors and topical minoxidil are FDA-approved treatments for AGA; benefits of additional treatments including dietary modification, exercise and nutritional supplements are still inconclusive based on available evidence (4).

Physicians often consider AGA to be a relatively mild dermatological condition, yet for affected individuals it can have tremendous negative impacts. Patients with AGA often experience psychological distress, negative body image perceptions and even depression(57). Most previous studies about the impacts of AGA have been conducted in adults, but hair loss symptoms usually start after puberty and continue progressively (8). A study done by Cash TF et al. in 1992 suggested that the impact of hair loss was greater among young men with earlier onset of hair loss (9). In this study, our primary objective was to investigate concerns about AGA on the lives of youth, its clinical relevance and how perspectives influence their personal well-being and health beliefs.

\section{Methods}

We conducted a single-center, cross-sectional questionnaire survey study among 4th to 6th year medical students enrolled at the Faculty of Medicine, Chulalongkorn University, Bangkok Thailand. This study was approved by the Institutional Review Board, Faculty of Medicine, Chulalongkorn University (IRB 441/59).

A closed-end questionnaire was developed for this study. The first part asked about socio-demographics data and survey participants were asked to self-grade the clinical severity of their own, and their same gender 1st degree relatives' hair loss using the NorwoodHamilton scale for men and Ludwig classification for women $(10,11)$. The second part asked about their concerns toward AGA and AGArelated quality of life, using the dermatology life quality index (DLQI), with higher scores indicating worse quality of life(12). The final part of the questionnaire asked about their personal beliefs regarding how food can affect AGA, and their treatment-seeking behaviours.

Latent class analysis $(\operatorname{LCA})(13,14)$ was used for the analyses. LCA is a statistical method used to group subjects into unobserved classes or categories that are similar for subjects within classes, based on observed measures or responses to a set of variables or questions. The objective of LCA is to find the smallest number of classes that the subjects within classes are similar to one another but distinct from the subjects in other classes. We used LCA to explore the number of latent classes based on the participants' answers on the following questions:

1. Are you concerned about your own hair loss?

2. Are you concerned that you will have hair loss in the future?

Page 2/11 
3. Are you concerned that if you have any children, they will have a hair problem?

4. Are you concerned about your relative's hair loss problem?

5. Are you concerned about your best friend's hair loss problem?

6. Are you concerned that other people will make fun of your hair?

7. Are you concerned about how your hair looks when you are swimming?

8. Are you concerned about how your hair looks when you are photographed?

9. Are you concerned about how your hair looks when you are flirting with someone?

10. Are you concerned about how your hair looks when you are with your boyfriend or girlfriend?

11. Have you ever considered getting a hair transplant?

Participants with missing data in any of these questions were excluded. The optimal number of classes was determined by comparing the convergence of iterative routines for parameter estimation and goodness-of-fit statistics (Akaike's information criteria (AIC), the corrected AIC, the Bayesian information criteria (BIC) and the adjusted BIC. LCA produces predicted probabilities of each class for each subject, with the final class membership of each subject is determined by the highest predicted probability ensuring each subject is assigned to only one class. After determining the number of classes, we compared classes regarding the distribution of sociodemographic factors (gender, number of hair products used, number of people you interact with per day), disease severity and duration of disease using Pearson chi-square for categorical covariates, and Kruskal-Wallis tests for continuous covariates. To identify the associations between the above-listed variables and membership in each class, we use multinomial logistic regression to quantitate relative risks and $95 \%$ confidence intervals $(95 \% \mathrm{Cl})$. The dependent variable was the latent class. Summary data for AGA-related quality of life, personal beliefs about how whether food can affect AGA, and their treatment-seeking behaviours of each class were analyzed and presented as proportions. All comparisons were two-sided, and P-value $<0.05$ was considered significant. All analyses were performed using STATA version 15.1 (StataCorp, College Station, TX).

\section{Results}

A total of 305 questionnaires were answered. As the LCA's classification method can be applied only to the subjects with complete data, we confined our analysis to $278(91 \%)$ respondents without any missing data in the questions mentioned above. The mean age of respondents was 22 (SD 0.79) years. The majority (57\%) of the participants were men. Of 278 participants, $59 \%$ had a monthly income of 200-400 USD, $66 \%$ did not use any hairstyling product and 75\% interacted with $11-100$ people per day. 147 (92.5\%) men and 116 $(97.5 \%)$ women reported any hair loss; the majority of both men and women who reported hair loss reported AGA severity of grade 1-2, with $61 \%$ reporting a duration of AGA of $>6$ months but less than 5 years. Almost $80 \%$ of the subjects had a same gender 1 st degree relative with a hair loss problem.

\section{Latent class analysis and characteristics of each class}

In total, 3 latent classes were fitted to the data. (Table 1) reports the conditional probabilities of the 11 previously selected indicators among the three LCs, interpreted as the probability of each indicator being present in the members of each class. Of 278 subjects, 162 (58\%) belonged to LC1, 62 (22\%) belonged to LC2 and 55 (20\%) belonged to LC3. LC1 subjects had the lowest probabilities of concerns regarding AGA. In LC2 subjects, probabilities of AGA concerns were low in general, except when they were flirting, when they were with their lovers and regarding how their hair looked in photos. LC3 subjects were most concerned about AGA. Consequently, we chose the following terms to designate the three classes: LC1, "Concern-free”; LC2, "Lover"; LC3 "Worrisome". 
Table 1

Parameter estimates for the three latent classes solution in 278 subjects

\begin{tabular}{|c|c|c|c|c|}
\hline & $\begin{array}{l}\text { Prevalence of indicators among the } 278 \\
\text { subjects, } \\
\text { N (\%) }\end{array}$ & $\begin{array}{l}\text { LC1 } \\
\text { Concern- } \\
\text { free } \\
(\mathrm{N}=162)\end{array}$ & $\begin{array}{l}\text { LC2 } \\
\text { Lover } \\
(\mathrm{N}= \\
62)\end{array}$ & $\begin{array}{l}\text { LC3 } \\
\text { Worrisome } \\
(\mathrm{N}=55)\end{array}$ \\
\hline Probability of membership in each class & & 0.58 & 0.22 & 0.20 \\
\hline \multicolumn{5}{|l|}{ Conditional probabilities ${ }^{1}$ of: } \\
\hline -concern about current hair loss problem & 17.27 & 0.04 & 0.03 & 0.73 \\
\hline -concern about hair loss in the future & 36.33 & 0.18 & 0.27 & 0.99 \\
\hline $\begin{array}{l}\text {-concern about hair loss in your future } \\
\text { children }\end{array}$ & 15.11 & 0.05 & 0.06 & 0.55 \\
\hline -concern about a relative's hair loss & 36.69 & 0.24 & 0.31 & 0.8 \\
\hline concern about a best friend's hair loss & 21.22 & 0.07 & 0.23 & 0.61 \\
\hline $\begin{array}{l}\text {-concern that other people will make fun of } \\
\text { your hair }\end{array}$ & 14.03 & 0.01 & 0.17 & 0.49 \\
\hline -concern about hair during swimming & 16.91 & 0.02 & 0.31 & 0.44 \\
\hline -concern about how your hair looks in photos & 36.33 & 0.08 & 0.79 & 0.73 \\
\hline -concern about hair when flirting & 34.53 & 0.02 & 0.97 & 0.60 \\
\hline $\begin{array}{l}\text {-concern about hair when you are with your } \\
\text { lovers }\end{array}$ & 34.17 & 0.01 & 0.95 & 0.63 \\
\hline -consider getting a hair transplant & 9.71 & 0.02 & 0.03 & 0.4 \\
\hline
\end{tabular}

(Table 2) compares the subjects' socio-demographic data and disease characteristics across the three LCs. The Worrisome class (LC3) had distinct characteristics of higher income, they used more hair styling products and interacted with a greater number of people per day. The severities of AGA in both men and women were also significantly higher in this group. The Concern-free and the Lover classes had quite similar characteristics in terms of income per month, use of hair styling products, number of people they interact with per day, and the severities of AGA in males and females. The proportion of subjects with same gender 1 st degree relative with hair loss problem were relatively high in all classes. The duration of AGA was longest in the Worrisome class (LC3) followed by the Lover class (LC2), then the Concern-free class (LC1). 
Table 2

Univariate comparisons of patients and disease characteristics among three latent classes identified in 278 subjects

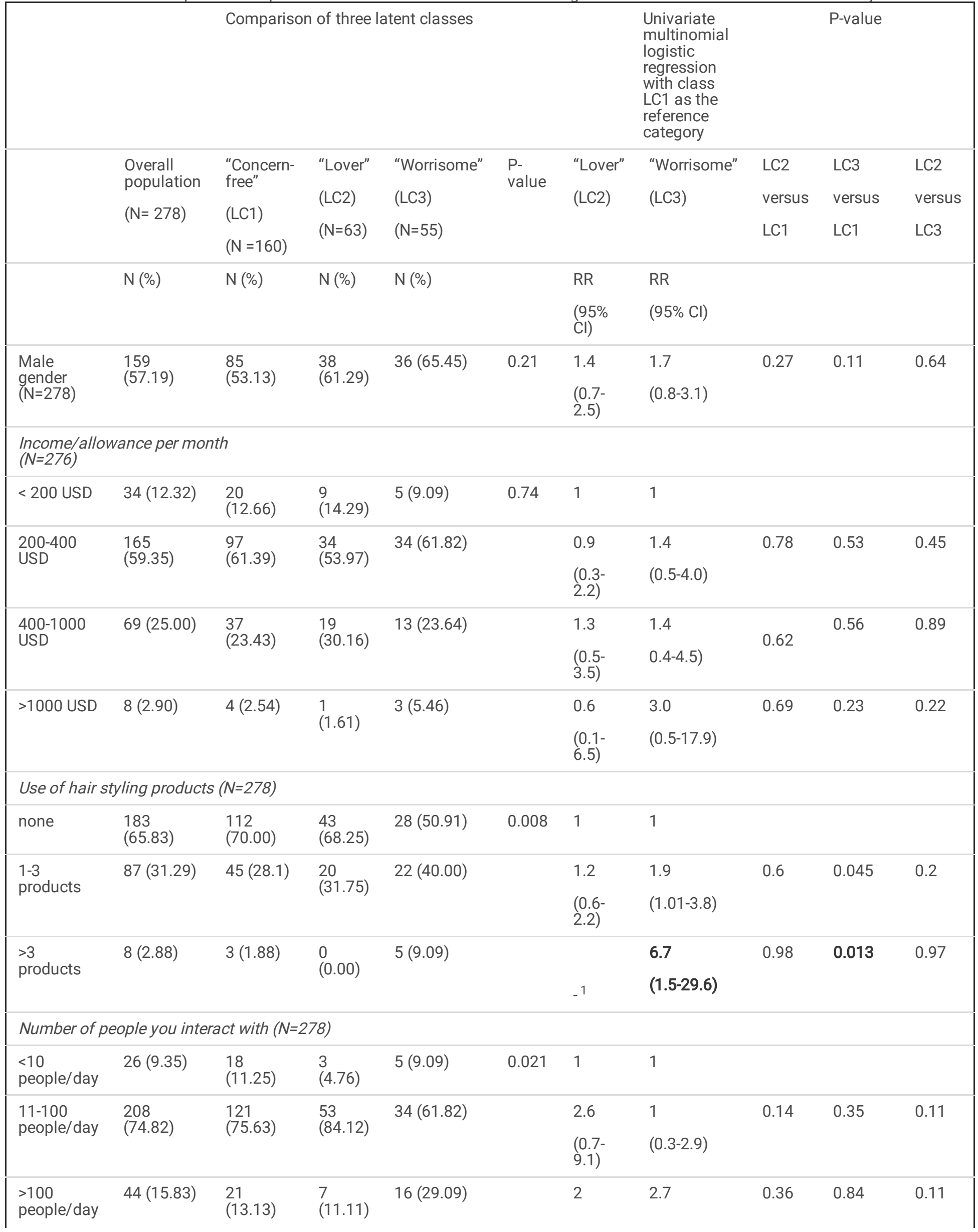

Page 5/11 
$(0.4-\quad(0.8-8.9)$

Male's AGA severity by Norwood-Hamilton

scale $(N=147)^{2}$

\begin{tabular}{|c|c|c|c|c|c|c|c|c|c|c|}
\hline grade $1-2$ & $\begin{array}{l}128 \\
(87.07)\end{array}$ & $\begin{array}{l}70 \\
(89.74)\end{array}$ & $\begin{array}{l}34 \\
(97.14)\end{array}$ & $24(70.59)$ & 0.016 & 1 & 1 & & & \\
\hline grade $3-5$ & 19 (12.93) & $8(10.26)$ & $\begin{array}{l}1 \\
(2.86)\end{array}$ & $10(29.41)$ & & $\begin{array}{l}0.2 \\
(0.3- \\
1.9)\end{array}$ & $\begin{array}{l}3.2 \\
(1.1-8.9)\end{array}$ & 0.17 & 0.023 & 0.014 \\
\hline
\end{tabular}

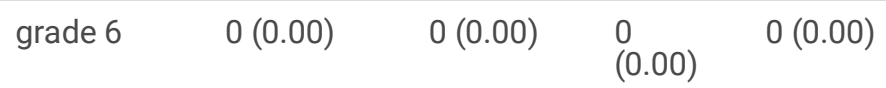

Female's AGA severity by Ludwig classification $(N=116)^{3}$

\begin{tabular}{|c|c|c|c|c|c|c|c|c|c|c|}
\hline grade $1-2$ & 92 (79.31) & $\begin{array}{l}64 \\
(86.49)\end{array}$ & $\begin{array}{l}19 \\
(90.48)\end{array}$ & 8 (42.10) & 0.001 & 1 & 1 & & & \\
\hline grade $3-5$ & 24 (20.69) & $\begin{array}{l}10 \\
(13.51)\end{array}$ & $\begin{array}{l}3 \\
(14.29)\end{array}$ & $11(57.89)$ & & $\begin{array}{l}0.9 \\
(0.2- \\
3.9)\end{array}$ & $\begin{array}{l}10.2 \\
(3.3-31.0)\end{array}$ & 0.96 & $<0.0001$ & 0.002 \\
\hline
\end{tabular}

$\begin{array}{lllll}\text { grade } 6-9 & 0(0.00) & 0(0.00) & \begin{array}{l}0 \\ (0.00)\end{array} & 0(0.00)\end{array}$

Same gender $7^{\text {st }}$ degree relative with hair loss problem $(N=278)$

$\begin{array}{lllllllll}\text { no } & 57(20.50) & 32 & 14 & 11(20.00) & 0.929 & 1 & 1 & \\ & & (20.00) & (22.22) & & & & \\ \text { yes } & 221 & 128 & 49 & 44(80.00) & & 0.8 & 1 & 0.71 \\ & (79.50) & (80.00) & (77.78) & & (0.4-\quad & (0.5-2.2)\end{array}$

Duration of $A G A(N=77)^{4}$

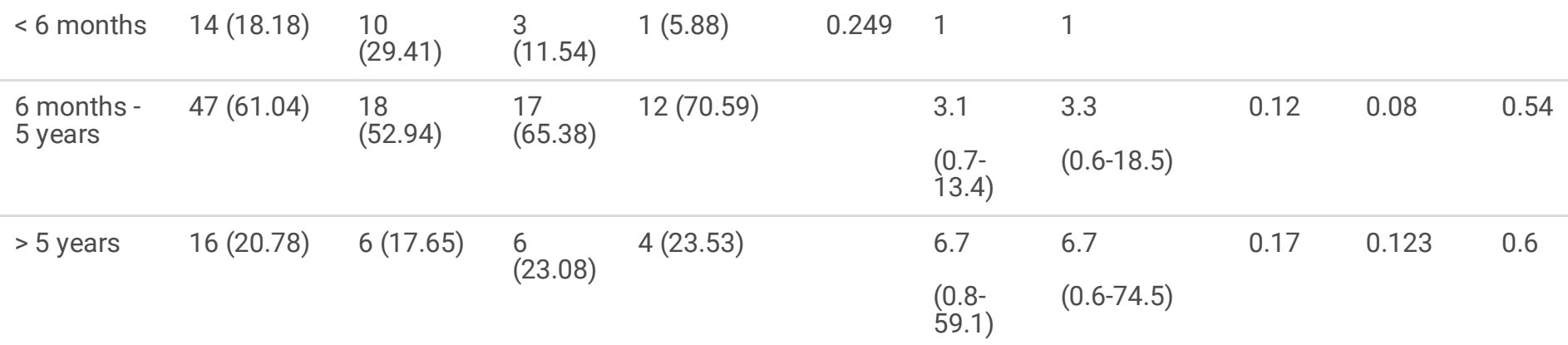

${ }^{1}$ cannot be estimated due to zero cell count

${ }^{2}$ excluding 12 people who have no disease: 7 in LC1, 3 in LC2 and 2 in LC3

${ }^{3}$ excluding 3 people who have no disease: 1 in LC1 and 2 in LC2

${ }^{4}$ only 77 people answered this question

\section{How AGA affects the youths' quality of life}

(Table 3) demonstrates the burden of AGA-related quality of life was highest in the Worrisome class (LC3) with $20 \%$ having more than 5 points in DLQI, compared to only $2.5 \%$ and $3.23 \%$ in the Concern-free class (LC1) and in the Lover class (LC2), respectively. 
Table 3

Association between three LC and AGA-related qualityof life, beliefs about foods, and treatment-seeking behaviours

\begin{tabular}{|c|c|c|c|}
\hline & $(\mathrm{N}=160)$ & $(N=63)$ & $(N=55)$ \\
\hline & $\mathrm{N}(\%)$ & $\mathrm{N}(\%)$ & $N(\%)$ \\
\hline \multicolumn{4}{|c|}{ AGA-related quality of life burden $(N=277)$} \\
\hline 0 points & $119(74.37)$ & $47(75.80)$ & $18(32.73)$ \\
\hline $1-5$ points & $37(23.13)$ & $13(20.97)$ & $26(47.27)$ \\
\hline$>5$ points & $4(2.50)$ & $2(3.23)$ & $11(20.00)$ \\
\hline \multicolumn{4}{|c|}{ Beliefs about these foods that it can worsen AGA $(N=276)$} \\
\hline \multicolumn{4}{|c|}{ Monosodium glutamate } \\
\hline no & $87(54.72)$ & $31(49.21)$ & $22(40.74)$ \\
\hline yes & $72(45.28)$ & $32(50.79)$ & $32(59.26)$ \\
\hline \multicolumn{4}{|l|}{ High fat diets } \\
\hline no & $151(94.97)$ & $59(93.65)$ & $45(83.33)$ \\
\hline yes & $8(5.03)$ & $4(6.35)$ & $9(16.67)$ \\
\hline \multicolumn{4}{|l|}{ Chocolate } \\
\hline no & $156(98.11)$ & $61(96.83)$ & $52(96.30)$ \\
\hline yes & $3(1.89)$ & $2(3.17)$ & $2(3.70)$ \\
\hline \multicolumn{4}{|c|}{ Beliefs about these foods that it can improve AGA $(N=275)$} \\
\hline \multicolumn{4}{|l|}{ Vitamin supplement } \\
\hline no & $132(85.54)$ & $48(76.19)$ & $40(74.07)$ \\
\hline yes & $26(16.46)$ & $15(23.81)$ & $14(25.93)$ \\
\hline \multicolumn{4}{|c|}{ The urgency of AGA treatment $(\mathrm{N}=77)$} \\
\hline not urgent & $32(94.12)$ & $25(96.15)$ & $14(85.35)$ \\
\hline urgent & $2(5.88)$ & $1(3.85)$ & $3(17.65)$ \\
\hline \multicolumn{4}{|c|}{ Percentage of income per month to spend for AGA treatment $(N=272)$} \\
\hline$<10$ & $126(81.29)$ & $48(77.42)$ & $27(50.00)$ \\
\hline $10-40$ & $25(16.12)$ & $13(20.97)$ & $22(40.74)$ \\
\hline $40-70$ & $1(0.65)$ & $0(0.00)$ & $1(1.85)$ \\
\hline$>70$ & $0(0.00)$ & $1(1.61)$ & $1(1.85)$ \\
\hline > one-month income & $3(1.94)$ & $0(0.00)$ & $3(5.56)$ \\
\hline \multicolumn{4}{|c|}{ Willing to live a healthier life if it's help improving AGA $(N=268)$} \\
\hline no & $130(85.53)$ & $43(69.35)$ & $34(64.15)$ \\
\hline yes & $22(14.47)$ & $19(30.65)$ & 19 (35.85) \\
\hline
\end{tabular}

More than $67 \%$ of the subjects in the Worrisome class reported at least one aspect of their daily life that was affected by their AGA condition, versus less than $25 \%$ in the other two classes. Most affected aspects of quality of life in all three classes were similar, their social characteristics and their self-confidence (data not shown).

Personal perspective about food and its effect on AGA in each class 
Personal beliefs about food and lifestyle among each class are shown in (Table 3). The Worrisome class (LC3) were most likely to believe that all the listed foods or ingredients, namely monosodium glutamate, high fat diets, chocolate and vitamin supplements, had some effects on AGA, versus the other classes. The Concern-free class (LC1) were least likely to believe that any of the listed foods could help or worsen their AGA condition. Of all the listed foods, the food additive monosodium glutamate was considered by all three LCs consider as something that could possibly worsen their AGA condition.

\section{Treatment-seeking behaviours in each class}

For treatment-beliefs and behaviours, a higher percentage of subjects in the Worrisome class (LC3) thought it was important to treat AGA urgently, compared to the other two classes. They were willing to spend more money on AGA treatment with more than $5 \%$ of the subjects willing to spend more than their entire monthly income on treatment. Half of the LC3 group were also willing to spend more than $10 \%$ of their one-month income on AGA treatment, versus only approximately $20 \%$ of the other two classes.

Interestingly more than $30 \%$ of the Worrisome class (LC3) and the Lover class (LC2) were willing to live a healthier life if it would improve their AGA condition, while only $14.5 \%$ of the Concern-free class (LC1) considered to do so.

\section{Discussion}

This is the first study to use latent class analysis to describe the effect of AGA-concerns in youths. Using the data from a cross-sectional survey, we were able to categorize youths into three distinct classes which are explicable and relevant to clinical practice. The first class, the "Concern-free" class (LC1), accounted for $58 \%$ of all subjects and was characterized by a low-level of concern about AGA. Even though the prevalence of Grade 1-2 AGA was high amongst our entire student cohort, this class showed low levels of interest in all AGArelated matters. The second, "Lover" class (LC2, 22\%) was characterized by a high level of AGA concern only when they are flirting or with their lovers and when considering how their hair appeared in photos. They had these concerns despite the fact that their AGA severities were not different from the Concern-free class (LC1), and more than one-third of the subjects in this group were willing to live a healthier life if it would help with their conditions. In contrast, the third "Worrisome" class (LC3), had the highest commitment and determination to improve the condition and also a higher proportion of both males and females with grade 3-5 AGA severity. This Worrisome class (LC3, 20\%) represented the class where participants were most concerned about AGA in every aspect. The increased AGA severity and number of hair products they used were statistically significantly higher than the Concern-free class (LC1). Their AGArelated quality of life was poorest compared to the other two classes, and they harbored beliefs that food and lifestyle impacted on AGA and were willing to spend more money for the treatments.

AGA has been stigmatized as a dermatological condition that significantly affects self-image satisfaction, with a negative impact on patients' well-being $(5,8,15)$. Although few studies have examined how concerning thoughts about AGA impact on quality of life, higher disease severity and higher impacts on quality of life have been observed in groups that are more concerned about AGA. For example, a previous prospective, multicenter study, reported that the quality of life of AGA patients decreased as severity of AGA increased(5). This emphasizes the importance of addressing AGA concerns in clinical practice. Our study showed that youths who are more concerned about AGA also think it is important to treat their AGA urgently. Indeed, treatment which is initiated early leads to a better response rates and clinical outcomes(16).

Our study also found that the group who was more concerned about AGA used more of hair products. However, we definitely cannot conclude whether their condition led these participants to seek products they believed might help improve their looks, or whether those products might be a factor contributing to their conditions. Nevertheless, this is an important discussion point, since one main obstacle to optimal AGA treatment outcomes is believed to be poor compliance and lack of adherence to the treatment regimens(17). Our result could imply that the patients, particularly youths, with more AGA-related concerns are more likely to adhere to therapies because of their usual complex hair care regimens. Incorporating topical drugs such as minoxidil, an FDA-approved treatment, could provide an efficient and user-friendly treatment for AGA in this group(18).

Other than negative social impact, AGA has been suggested as a potential risk factor for asymptomatic atherosclerosis, myocardial infarction, and metabolic syndromes $(19,20)$. Microvascular insufficiency theory has been proposed as one of the mechanisms $(21,22)$. An excessive of circulating insulin causing vasoconstriction results in increased peripheral resistance, which decreases the blood supply to the scalp and enhances the effect of dihydrotestosterone on follicular miniaturization is one proposed mechanism(23). The link between AGA and metabolic disease is even stronger in the group of patients with early onset AGA(24-26). Even though an association between healthy lifestyle and AGA is still not clear, evidence about the associations between healthy living and its benefit in 
cardiovascular disease and metabolic disease prevention are well recognized(27-29). We therefore propose that it is important to encourage any youths with concerns about AGA, to live a healthier life not because it can help their AGA condition, but because it can help minimizing the increased cardiovascular disease and metabolic disease in this group of patients.

Our study is the very first to focus on androgenetic alopecia concerns in youths. Most about AGA concerns and impact have been conducted in middle-aged subjects $(5,30-33)$. A previous study found AGA affected over $70 \%$ of adult males and $50 \%$ of adult women (34). However, in this study, we found that $92.5 \%$ of men and $97.5 \%$ of women in their twenties reported hair loss considered as AGA. We cannot definitively conclude presence and severity of AGA in our study participants, since the data was collected by self-report. Although this might cause controversy regarding diagnostic accuracy, it nevertheless reflects the perception of the students towards their conditions, and the impacts on their lives. This is important from an ethical point of view, since it is essential to consider whether people who have concerns about AGA should be treated as healthy, if their conditions are relatively mild, given their concerns have proven effects on their well-being and health-seeking behaviours.

The concept of sickness should refer to the social and societal dimensions of an ailment; It is about the perceptions and subjective feelings of those with the condition, not only the severity of disease. This research further emphasizes the significance of patient perspectives on AGA. Furthermore, our findings are based on a classification method involving no pre-established definitions and suggest three distinct group of concern regarding AGA in youths. These three subtypes, "Concern-free", "Lover" and "Worrisome", are consistent with those observed in clinical experience and provide a useful classification for clinicians to integrate into the clinical practice for better understanding and treatment outcomes in youths with AGA. For a pragmatic use of classifications in real-life practice, we suggest that the 11-point questionnaires could be shortened into 4 most distinct topics (from parameter estimation, Table 1.): concern about hair loss in the future or concern about a relative's hair loss to include them in the "Concern-free" class (LC1) concern about hair when flirting or when you are with your lovers to include them in the "Lover" class (LC2). If all the answers to these topics are no, include them in the "Concern-free" class (LC1). Further prospective studies should be conducted to evaluate the benefit of incorporating these classifications which could be determined by administration of a short questionnaire, into real-world treatments for AGA, to assess treatment adherence and clinical outcomes after treatments, in participants from each class.

\section{Conclusions}

More than $90 \%$ of youths reported the hair loss considered as AGA. Youths who are more worried about AGA have experienced higher severity of AGA, worse AGA-related quality of life, and are more likely to use multiple hair products. LCA which was used to classify 3 groups of AGA in the youths based on their concerns might be useful for integrating into the clinical practice to assess adherence and outcomes after treatment. Further research should be focused on prospective evaluating the advantage of these classifications.

\section{Abbreviations}

AGA: androgenic alopecia; LCA: latent class analysis; DLQI: dermatology life quality index ; LC1: latent class 1 or concern-free class; LC2: latent class 2 or lover class; LC3: latent class 3 or worrisome class.

\section{Declarations}

\section{Ethics approval and consent to participate:}

The study was approved by the institutional Review Board, Faculty of Medicine, Chulalongkorn University (IRB 441/59). Informed consent to participate in the study was obtained from all participants.

\section{Consent for publication.}

Not applicable.

\section{Availability of data and materials.}

The datasets used and/or analysed during the current study are available from the corresponding author on reasonable request. 


\section{Acknowledgements.}

Not applicable.

\section{Funding.}

Thu authors have no financial support for this study.

\section{Author's contributions.}

BC: Conceptualization, Methodology, Investigation, Resources, Writing-Original draft, Visualization, Supervision, Project administration; SK: Conceptualization, Methodology, Data curation, Formal analysis, Software, Validation, Resources, Writing- Review \& editing; CN: Conceptualization, Methodology, Validation, Data curation, Writing- Review \& editing; PA: Conceptualization, Methodology, Validation, Resources, Writing- Review \& editing; KP: Conceptualization, Methodology, Investigation, Data curation, Resources, Validation, WritingReview \& editing. All authors read and approved the final manuscript.

\section{Competing interests.}

The authors declare that they have no competing interests.

\section{References}

1. Jang WS, Son IP, Yeo IK, Park KY, Li K, Kim BJ, et al. The annual changes of clinical manifestation of androgenetic alopecia clinic in korean males and females: a outpatient-based study. Annals of dermatology. 2013;25(2):181-8.

2. Sawaya ME, Price VH. Different levels of 5alpha-reductase type I and II, aromatase, and androgen receptor in hair follicles of women and men with androgenetic alopecia. The Journal of investigative dermatology. 1997;109(3):296-300.

3. Levy-Nissenbaum E, Bar-Natan M, Frydman M, Pras E. Confirmation of the association between male pattern baldness and the androgen receptor gene. European journal of dermatology : EJD. 2005;15(5):339-40.

4. Bienova M, Kucerova R, Fiuraskova M, Hajduch M, Kolar Z. Androgenetic alopecia and current methods of treatment. Acta dermatovenerologica Alpina, Pannonica, et Adriatica. 2005;14(1):5-8.

5. Han SH, Byun JW, Lee WS, Kang H, Kye YC, Kim KH, et al. Quality of life assessment in male patients with androgenetic alopecia: result of a prospective, multicenter study. Annals of dermatology. 2012;24(3):311-8.

6. Cartwright T, Endean N, Porter A. Illness perceptions, coping and quality of life in patients with alopecia. The British journal of dermatology. 2009;160(5):1034-9.

7. Sawant N, Chikhalkar S, Mehta V, Ravi M, Madke B, Khopkar U. Androgenetic alopecia: quality-of-life and associated lifestyle patterns. International journal of trichology. 2010;2(2):81-5.

8. Wang TL, Zhou C, Shen YW, Wang XY, Ding XL, Tian S, et al. Prevalence of androgenetic alopecia in China: a community-based study in six cities. The British journal of dermatology. 2010;162(4):843-7.

9. Cash TF. The psychological effects of androgenetic alopecia in men. J Am Acad Dermatol. 1992;26(6):926-31.

10. Norwood OT. Incidence of female androgenetic alopecia (female pattern alopecia). Dermatologic surgery : official publication for American Society for Dermatologic Surgery [et al]. 2001;27(1):53-4.

11. Ludwig E. Classification of the types of androgenetic alopecia (common baldness) occurring in the female sex. The British journal of dermatology. 1977;97(3):247-54.

12. Finlay AY, Khan GK. Dermatology Life Quality Index (DLQI)-a simple practical measure for routine clinical use. Clin Exp Dermatol. 1994;19(3):210-6.

13. Rindskopf D, Rindskopf W. The value of latent class analysis in medical diagnosis. Statistics in medicine. 1986;5(1):21-7.

14. Formann AK, Kohlmann T. Latent class analysis in medical research. Statistical Methods in Medical Research. 1996;5(2):179-211.

15. Zhang M, Zhang N. Quality of life assessment in patients with alopecia areata and androgenetic alopecia in the People's Republic of China. Patient preference and adherence. 2017;11:151-5. 
16. Sinclair R, Patel M, Dawson TL, Jr., Yazdabadi A, Yip L, Perez A, et al. Hair loss in women: medical and cosmetic approaches to increase scalp hair fullness. The British journal of dermatology. 2011;165 Suppl 3:12-8.

17. Lulic Z, Inui S, Sim WY, Kang H, Choi GS, Hong W, et al. Understanding patient and physician perceptions of male androgenetic alopecia treatments in Asia-Pacific and Latin America. J Dermatol. 2017;44(8):892-902.

18. Goren A, Naccarato T. Minoxidil in the treatment of androgenetic alopecia. Dermatol Ther. 2018;31(5):e12686.

19. Cotton SG, Nixon JM, Carpenter RG, Evans DW. Factors discriminating men with coronary heart disease from healthy controls. British heart journal. 1972;34(5):458-64.

20. Shahar E, Heiss G, Rosamond WD, Szklo M. Baldness and myocardial infarction in men: the atherosclerosis risk in communities study. American journal of epidemiology. 2008;167(6):676-83.

21. Goldman BE, Fisher DM, Ringler SL. Transcutaneous PO2 of the scalp in male pattern baldness: a new piece to the puzzle. Plastic and reconstructive surgery. 1996;97(6):1109-16.

22. Arias-Santiago S, Gutiérrez-Salmerón MT, Castellote-Caballero L, Buendía-Eisman A, Naranjo-Sintes R. Androgenetic alopecia and cardiovascular risk factors in men and women: A comparative study. Journal of the American Academy of Dermatology. 2010;63(3):420-9.

23. Klemp P, Peters K, Hansted B. Subcutaneous blood flow in early male pattern baldness. The Journal of investigative dermatology. 1989;92(5):725-6.

24. Banger HS, Malhotra SK, Singh S, Mahajan M. Is early onset androgenic alopecia a marker of metabolic syndrome and carotid artery atherosclerosis in young Indian male patients? International journal of trichology. 2015;7(4):141-7.

25. Chakrabarty S, Hariharan R, Gowda D, Suresh H. Association of premature androgenetic alopecia and metabolic syndrome in a young Indian population. International journal of trichology. 2014;6(2):50-3.

26. Matilainen VA, Makinen PK, Keinanen-Kiukaanniemi SM. Early onset of androgenetic alopecia associated with early severe coronary heart disease: a population-based, case-control study. Journal of cardiovascular risk. 2001;8(3):147-51.

27. Blumenthal JA, Emery CF, Madden DJ, George LK, Coleman RE, Riddle MW, et al. Cardiovascular and behavioral effects of aerobic exercise training in healthy older men and women. Journal of gerontology. 1989;44(5):M147-M57.

28. Visioli F, Hagen TM. Nutritional strategies for healthy cardiovascular aging: Focus on micronutrients. Pharmacological Research. 2007;55(3):199-206.

29. Liu K, Daviglus Martha L, Loria Catherine M, Colangelo Laura A, Spring B, Moller Arlen C, et al. Healthy lifestyle through young adulthood and the presence of low cardiovascular disease risk profile in middle age. Circulation. 2012;125(8):996-1004.

30. Severi G, Sinclair R, Hopper JL, English DR, McCredie MRE, Boyle P, et al. Androgenetic alopecia in men aged 40-69 years: prevalence and risk factors. British Journal of Dermatology. 2003;149(6):1207-13.

31. Gonul M, Cemil BC, Ayvaz HH, Cankurtaran E, Ergin C, Gurel MS. Comparison of quality of life in patients with androgenetic alopecia and alopecia areata. Anais brasileiros de dermatologia. 2018;93(5):651-8.

32. Mubki T, Dayel S, AlHargan A, AlGhamdi K, AlKhalifah A. Quality of life and willingness-to-pay in patients with androgenetic alopecia. Egypt J Dermatol Venereol. 2019;39(1):31-6.

33. Cash TF, Price VH, Savin RC. Psychological effects of androgenetic alopecia on women: Comparisons with balding men and with female control subjects. Journal of the American Academy of Dermatology. 1993;29(4):568-75.

34. Price VH. Androgenetic Alopecia in Women. Journal of Investigative Dermatology Symposium Proceedings. 2003;8(1):24-7. 